\title{
RELATIVE OR ABSOLUTE POVERTY LINES: A NEW APPROACH
}

\author{
By David MadDen \\ University College Dublin
}

\begin{abstract}
When measuring poverty over time analysts must choose the value of the income elasticity of the poverty line, which essentially determines whether an absolute or relative poverty line is being used. The choice of this parameter is ultimately a value judgement, but this paper suggests an approach which has some empirical basis. Borrowing from the life-style and deprivation approach to poverty, various dimensions of poverty and deprivation are identified and the income elasticity of these items is used as the income elasticity of the poverty line. Data from the 1987 and 1994 Irish Household Budget Surveys suggest an upper bound of 0.7 for this parameter. Poverty measures using a number of values of the income elasticity of the poverty line are presented and test statistics are presented to determine whether observed differences in poverty measures are statistically significant.
\end{abstract}

\section{INTRODUCTION}

In recent years Ireland has witnessed unprecedented rates of economic growth. ${ }^{1}$ Despite these record growth rates, concern has been expressed that not everyone has participated in the fruits of economic success. ${ }^{2}$ There is anxiety that measured poverty rates may have risen in recent years as the less well-off have been excluded from the increased prosperity. The difficulty with evaluating such concerns is that there are different ways of measuring poverty and the result obtained is frequently dependent upon the particular measure adopted. ${ }^{3}$

As has been documented by Sen (1976) and others, the measurement of poverty typically involves two choices: first a poverty line has to be chosen (the identification issue) and secondly a method has to be found for obtaining a single summary statistic on the basis of the information concerning those families identified as poor i.e. those below the poverty line (the aggregation issue). ${ }^{4}$ This offers the analyst two degrees of freedom in choice of poverty measure. Firstly there is the location of the poverty line, and in particular the choice of an absolute line (i.e. one that is fixed over time) or a relative line (one which is typically expressed as a fraction of some central measure of income such as the mean or median). In

Note: I would like to thank Anthony Murphy and two anonymous referees for helpful comments. I remain responsible for any errors. I acknowledge Central Statistics Office-Household Budget Survey Anonymised as the source of data used in this paper.

${ }^{1}$ For example, see Gray (1997)

${ }^{2}$ See Callan, Nolan and Walsh (1998).

${ }^{3}$ For example in the recent ESRI volume (Callan et al., 1996) simple headcount measures show a rise in poverty over the period $1987-94$, while measures which take account of the extent of shortfall below the poverty line show a fall in poverty. These measures are on the basis of a purely relative poverty line. If an absolute poverty line is chosen then poverty falls for all measures. See below for formal definitions of these terms.

${ }^{4}$ In practice there are other issues involved such as the choice of unit of observation, family or individual, and the choice of appropriate equivalence scale to adjust for family size and composition, but it seems fair to suggest that the identification and aggregation issues are those which provoke most debate. 
principle it is possible to choose what we term a hybrid line which combines features of both although this appears to be rare in practice. Secondly there is the choice of aggregator and this can range from a simple count of the numbers of units below the poverty line to more complicated measures which take account of the distribution of income amongst the poor.

In this paper we are interested in examining the sensitivity of poverty measures to the first of these issues, the choice of a relative or absolute poverty line. Our suggested solution to the issue borrows from an alternative view of poverty, which we can label the deprivation approach. This approach focuses on a small subset of items the absence of which from a household's consumption indicates the presence of basic deprivation. Research for Ireland suggests that this approach can lead to different results from those obtained using poverty lines. ${ }^{5}$ Our procedure utilises information from this approach to determine the extent to which the poverty line should be absolute, relative, or a hybrid.

Since poverty measures are estimated on sample data there will be associated standard errors and so in this paper we also address the extent to which observed differences in poverty measures are statistically significant.

The structure of the remainder of the paper is as follows: in Section Two we outline more formally the choice between an absolute and a relative poverty measure. In Section Three we show how the deprivation approach may be useful in determining the choice between an absolute, relative or hybrid poverty line. In Section Four we discuss our data and in Section Five we discuss our econometric specification and present results, including tests of significance, using data from the 1987 and 1994 Household Budget Surveys. In Section Six we present concluding comments.

\section{Poverty Lines: Absolute or Relative?}

Before we examine the issue posed in the title to this section, we will first introduce some notation. Let $\mathbf{y}$ be the vector of personal incomes for the community as a whole, assuming we have adjusted incomes for family size and composition etc., and let $z$ be the poverty-line income. The identification issue is then concerned with the identification of the value of $z$, the poverty line. Households with incomes below the poverty line are deemed to be poor and those above the poverty line are not poor. Perhaps the most important decision with regard to choice of a poverty line is that between an absolute or a relative poverty line, $z_{\mathrm{a}}$ or $z_{\mathrm{r}}$ respectively. An absolute poverty line may be defined with respect to the cost of purchasing a minimum basket of necessities and, as its name suggests, this basket may remain unchanged even though incomes as a whole in the population in question may be changing. Examples of such lines are the official poverty line in the U.S. In fairness, such poverty lines may be occasionally updated, so they cannot be regarded as absolute poverty lines in strictest interpretation of the word, but they are to be distinguished from poverty lines which are defined relative to a summary statistic of income/expenditure (see below).

As outlined above, even absolute poverty lines are rarely cast in stone in the sense that they are absolutely unchanging over time. Poverty lines may be updated

${ }^{5}$ See Chapter 6 in Callan et al. (1996). 
to reflect changes in the overall standard of living and expectations in society. Many people view it as unreasonable that what was accepted as a minimum standard of living fifty years ago should also be accepted today. Thus in some sense even absolute measures of the poverty line can be relative in that they may change over time. A purely relative measure is one that is defined as a certain fraction of some central summary statistic, e.g. the mean or median, of population incomes. ${ }^{6}$ Thus the poverty line may be set at, say, 50 percent of average income. Note that the adoption of such a measure does not amount to measuring inequality (although the poverty index in this case will only change if there is a change in the income distribution) and nor does it necessarily mean that "the poor are always with us" (see Atkinson, 1975), since if the income distribution becomes more compact it is possible that everybody will have an income in excess of 50 percent of the mean. However, the choice of a purely relative measure does imply that measured poverty is homogenous of degree zero in incomes. Thus a broadly based improvement in absolute living standards may not show up as a fall in measured poverty. A purely relative measure may also give rise to the anomaly that should average incomes decrease, then while absolute living standards are falling, measured poverty registers no change or may indeed fall.

Once the issue of the choice of poverty line has been resolved then, depending upon the method of aggregation used, the poverty index, $P(\mathbf{y} ; z)$, can be calculated. Note however, as pointed out by Foster (1998), the important distinction between the general concept underlying the choice of poverty line and the specific poverty line chosen. For comparisons over time, particularly if living standards are changing rapidly, the former is the more important issue, with the choice of the latter fairly arbitrary.

However, the choice of a poverty line does not have to be so stark between absolute or relative. It is possible to choose a hybrid between the two. We could adopt a weighted geometric average of a relative and an absolute threshold, $z=z_{r}^{\rho} z_{a}^{1-\rho}$ where $0<\rho<1$. This form of line has the property that a one percent increase in the central measure of income leads to a $\rho$ percent increase in the poverty line. Thus $\rho$ is the income elasticity of the poverty line and a value of $\rho$ equal to zero implies an absolute poverty line while a value equal to one implies a purely relative line. Thus, as Foster expresses it, the absolute/relative debate now becomes a question of "how relative?" with $\rho$ the relevant decision variable. If the poverty line is to be central in the setting of income support payments then the choice of $\rho$ may decide the extent to which the poor share in economic growth. But how do we choose $\rho$ ? Ultimately this is a normative question and as such there is no "right or wrong" answer. The authors of a recent study which addresses poverty in Ireland come down in favour of a value of one:

"... a strong argument can be made that, over time, increases in general living standards will come to be fully reflected in expectations about what is sufficient to participate fully in society. This means that real

${ }^{6}$ Note that the adoption of this approach implies that when making cross-country comparisons of poverty we are setting the poverty line for rich countries higher than for poor countries, a position with which some people may be uncomfortable. This issue is rarely pointed out, perhaps because different national accounts conventions with regard to definitions of income means that cross-country poverty comparisons are fraught with difficulties. 
income growth can have an impact in the short term, but over the long haul the only way to reduce poverty is to bring people closer to average living standards. This is represented crudely in a purely relative income poverty line, but in essence is also at the core of [measures] of poverty combining income and non-monetary indicators of deprivation...". (Callan, Nolan and Walsh, 1998).

On the other hand Foster claims that:

"An elasticity of 1 appears to be too high to command much political support in the United States"(Foster, 1998).

It is clear that there is room for considerable disagreement over a "reasonable" value for $\rho$. Is there any alternative approach which might help us find a value of $\rho$ which might command a degree of support? The next section addresses this question.

\section{The Deprivation Approach to Poverty}

As outlined above, one of the crucial issues in measuring poverty is the income elasticity of the poverty line. Is there any way in which this parameter can be recovered from household data? It is obviously possible to estimate income elasticities for individual goods or groups of goods but how does this help us find the income elasticity for a concept such as a poverty line? One possible approach is to borrow from an alternative way of evaluating poverty, what we termed above the "Deprivation" approach to poverty. This approach has its origins in the work of Townsend (1979) and rests on the idea that if people are so deprived as to lack the resources to participate in the customary activities in society and thus in some sense are excluded from society, then they may be regarded as being in poverty. To quote Townsend (1979):

Individuals, families and groups in the population can be said to be in poverty when they lack the resources to obtain the type of diets, participate in the activities, and have the living conditions and amenities which are customary, or at least widely encouraged and approved, in the societies to which they belong. Their resources are so seriously below those commanded by the average individual or family that they are in effect, excluded from ordinary living patterns, customs and activities. (Townsend, 1979, p.15.)

Note that to some extent Townsend's idea of deprivation embodies a relative concept of poverty. Since poverty is defined, in some loose sense, as exclusion from the "norm" in society, and presumably this norm changes over time, then so too will the definition of poverty. For example, forty years ago the possession of a television might not have constituted part of the norm, whereas it surely does now. ${ }^{7}$ However, deprivation does not necessarily involve a purely relative concept of poverty. For example, in times of rapid growth average income may be rising quite rapidly (and so too would a poverty line based on a percentage of it) but

\footnotetext{
${ }^{7}$ Note that we must be very careful when using this concept of poverty to distinguish between the case of people who do not own, say a television, out of choice, as opposed to those who do not own a television owing to lack of resources.
} 
this does not imply that what constitutes deprivation will also rise one-for-one with average income.

This begs the question of how our measure of deprivation should change in line with income, or, in other words, what is the income elasticity of deprivation? If we can find an appropriate estimate for this, then this would seem to be a strong candidate as a suitable measure for $\rho$. Thus, if we can identify the subset of goods, the absence of which constitute deprivation, then the income elasticity of this set of goods could be an appropriate measure for $\rho$, the income elasticity of the poverty line. Thus we equate the income elasticity of the poverty line with the income elasticity of those goods, the absence of which in a consumption bundle indicates deprivation. There are different approaches to selecting this set of goods. For example, Townsend focused on items or activities which were actually possessed by the majority, while Mack and Lansley (1985) selected items which people themselves identified as being necessities i.e. ". . . things which every household (or person) should be able to have and that nobody have to do without". ${ }^{8}$ The approach adopted by Callan et al. in their study of poverty in Ireland was essentially a compromise between these two positions. They look at items which were identified as being necessities by a majority of the population and also possessed by a majority of the population. ${ }^{9}$ Since we are also examining Irish data it makes sense to follow their procedure and indeed to use, as closely as possible, the list of items which they identified.

Callan et al. provide two different lists of items relating to life style and deprivation. One of these consists of 13 items which were identified as being necessities by a majority of the population and also possessed by a majority of the population, while the other list consists of the 23 items for which information was available in both of the years under consideration (1987 and 1994). Using factor analysis, they then construct three dimensions of deprivation i.e. they can identify three distinct groups defined by those items that are more highly correlated with each other that with the other items. The three dimensions so identified are: (1) basic life-style deprivation consisting of basic items such as food and clothes (2) secondary life-style deprivation consisting of items such as a car, telephone and leisure activities and (3) housing deprivation consisting of items related to housing quality and facilities.

Our contention in this paper is that income elasticities for the group of goods/activities identified in these dimensions of deprivation can provide "reasonable" values for $\rho$. They are reasonable in the sense that they have a basis in the observed responses of people as to what constitutes poverty. It is important to note that once again this approach will not identify the "original" poverty line but it will at least suggest how the poverty line should change over time.

\section{DAtA}

In this section we apply the ideas from Section 3 to data from the Irish Household Budget Surveys (HBS) of 1987 and 1994. These are nationally

\footnotetext{
${ }^{8}$ Townsend's approach was also adopted by Desai and Shah (1988).

${ }^{9}$ Note we are not trying to identify a representative consumption bundle for the poor. Instead we are trying to identify a set goods, the absence of which in a consumption bundle, would entail deprivation.
} 
representative surveys carried out every seven years and collect a variety of information concerning the consumption patterns, income and demographic characteristics of in excess of 7,000 households. Fortunately these years coincide with the years analysed by Callan et al. using the ESRI Living in Ireland Survey. Since the results from Callan et al. are based upon a different survey from the one we are using, our results are not directly comparable. Nevertheless, we would expect to see a strong correspondence between the results, given that the Living in Ireland survey is also nationally representative (albeit with a smaller sample size) and that many of the measures used in Living in Ireland (e.g. disposable income) correspond with those used in the HBS. ${ }^{10}$

Before proceeding with the analysis we must first decide upon our definition of "income" or more particularly whether to use income or expenditure. ${ }^{11}$ Broadly the issues are as follows: certain components of income are difficult to measure e.g. income from self-employment. ${ }^{12}$ Perhaps more importantly crosssection studies typically provide income measures which are snapshots in time and thus take no account of the difference between transitory and permanent income. Since consumption/expenditure decisions are usually made with reference to permanent income then expenditure measures may be preferable. However, such measures also have drawbacks. Expenditure on items such as alcohol and tobacco are typically under-reported. Also, as mentioned above, expenditure over a two-week period may not be a reliable measure of consumption, particularly for mature households who may have a large stock of durables from which they derive services.

However a further problem specific to the HBS is that income observations are "top-coded" i.e. values of income in excess of $£ 800$ per week are simply entered as $£ 800$ per week. Thus the distribution of income is censored on the right hand side at a value of $£ 800$. This causes problems both when estimating income elasticities and also when calculating a poverty line which is a certain percentage of mean income (it does not arise when using median income). One way around this problem is to find an appropriate instrument for income and then use predicted income rather than actual income for the calculation of income elasticities (the problem does not arise for expenditure). Thus given appropriate instruments for income we can carry out a Tobit regression of income on these variables (reflecting the censoring of income at £800) and then use predicted income from this Tobit. However, since the obvious candidate as an instrument for income is expenditure, it seems more sensible to simply use expenditure as the basis for calculating elasticities and the poverty line. ${ }^{13}$ Our expenditure measure is total expenditure excluding repayments of loans other than house purchase mortgages, savings and taxes. It includes the value of home grown food consumed.

Since we are examining expenditure decisions across families of differing sizes and composition it is necessary to adjust our measures of expenditure by the

\footnotetext{
${ }^{10}$ For a comprehensive description of the Living in Ireland survey, see Callan et al. (1996)

${ }^{11}$ For a recent discussion of poverty and inequality in Ireland which looks at measures of both income and consumption see O'Neill and Sweetman (1998).

${ }^{12}$ For a detailed discussion see Blundell and Preston (1998).

${ }^{13}$ However to facilitate comparison with the Callan et al. study we also present results for poverty measures based on disposable income.
} 
appropriate equivalence scale. There is an extensive literature on the appropriate choice of equivalence scale. ${ }^{14}$ Here we use a scale which has been widely used in poverty studies in the EU. It is the same as scale "C" used by Callan et al. (1996) and is also used by O'Neill and Sweetman (1998). The weights are 1 for the first adult in the household, 0.7 for additional people aged over 14 and 0.5 for people aged less than 14.

TABLE 1

LifE-STYle Deprivation IndiCATORs AND CORRESPONDING HBS Items

\begin{tabular}{ll}
\hline \hline ESRI Life-Style Deprivation Indicator & HBS Variable \\
\hline 1. Basic Dimension & \\
Go without heat & Presence of full/partial central heating (H67, \\
& H68), Space heating in winter (H277) \\
Go without substantial meal & n.a. \\
Debt/charity & n.a. \\
New not second hand clothes & T145-214 \\
Meal with meat/chicken/fish & T232-54, T505-520 \\
Warm, waterproof overcoat & T145-146, T164, T175-176, T199 \\
Two pairs of strong shoes & T162-163, T174, T197-198, T211 \\
Roast or equivalent once a week & T23-40 \\
2. Housing/Durables Dimension & \\
Bath/shower & H88 \\
Indoor toilet & H89 \\
Washing machine & H63 \\
Refrigerator & H65 \\
Colour TV & H62 \\
Dry, damp-free dwelling & n.a. \\
3. Secondary Dimension & \\
Annual holiday away from home & T573-578 \\
Ability to save regularly & T434 \\
Daily newspaper & T306 \\
Telephone & H61 \\
Hobby/leisure activity & n.a. \\
Central heating & Presence of full/partial central heating (H67, \\
Presents for family/friends once a year & T68), Space heating in Winter (H277) \\
Car & H70 \\
Afternoon/evening out in previous two weeks & T354-359 \\
\hline
\end{tabular}

Note: $\mathrm{H}$ refers to header variables in HBS survey while $\mathrm{T}$ refers to trailer variables.

To apply our suggested procedure from Section 3 we need to identify those variables or those pieces of information in the HBS which correspond most closely to the life-style and deprivation indicators of Callan et al. In Table 1 we present the detailed items identified by Callan et al. as constituting deprivation and what we believe is the most closely corresponding item in the HBS.

By and large the correspondence is quite close, particularly for the Housing and Durables dimension. In some cases there is no obvious corresponding item in the HBS e.g. reliance on charity or the presence of debt. The existence of a

\footnotetext{
${ }^{14}$ See Deaton and Muellbauer (1980) for a discussion.
} 
hobby or leisure activity is also too broad to be captured by the type of detail present in the HBS. The HBS will not tell us whether the household has been without heat or a substantial meal, though perhaps some information on these indicators can be gleaned from the data on central heating and meals with meat/ chicken/fish. ${ }^{15}$ One particular problem which arises is that for many items the HBS records expenditure on the item, whereas deprivation is defined as the absence of the item. Of course, the lack of expenditure on an item (e.g. warm overcoat, strong shoes) does not necessarily indicate its absence in a household, especially for items which may only be purchased infrequently. Nevertheless, presumably the purchase of such items will still be more concentrated amongst the better-off, so that income/expenditure elasticities may still be of interest here. This issue does not arise in the Housing and Durables dimension because here the HBS simply records the presence or absence of a durable such as a TV or washing machine.

Another issue which must be considered is how best to use all the available information. We have data for two years, 1987 and 1994. Thus in principle we could estimate total/expenditure elasticities using the pooled cross-section and time series data. However since we do not have price data we have no way of accounting for changes in relative prices over the 1987-94 period. Thus our expenditure elasticities estimated on pooled data may be biased. If we estimate separately for 1987 and 1994 then at least we can assume that there is no price variation.

However, it can be argued that people at different points in the income distribution may face different prices for the same goods. For example, some authors maintain that the poor pay more (see Caplovitz, 1967) and intuitively this is probably the case for goods such as credit. This would have implications for one of our indicators of deprivation (debt) since it implies that the cost of debt is higher for the poor than for the rich. However, owing to data limitations, it is simply not possible for us to take account of the different cost of debt/credit. From an econometric point of view, if prices do differ across the income distribution, then the omission of price variability from our Engel curves leaves us open to the possibility of omitted variables bias. The key issue here is whether prices are correlated with income. Intuitively it seems reasonable to assume that for the goods for which we will be carrying out econometric estimation, the assumption of common prices is a legitimate one and so prices and incomes are not correlated. This implies that we will have two estimates of expenditure elasticities for each deprivation category. However, as we will see below, results for the two years are very similar so our conclusions are not sensitive to whether we use 1987 or 1994 estimates.

This latter point raises the further issue of how to aggregate the various expenditure elasticities which will be calculated. Ideally we would like to construct a weighted average of the different elasticities but unfortunately for many items of deprivation we have no information on the relevant weight (e.g. for items such

\footnotetext{
${ }^{15}$ Of course a household may have central heating but lack the resources to use it as frequently as they wish.
} 
as bathroom/shower, toilet etc.). As we see below, it is possible to construct weighted averages for certain sub-categories of the basic dimension.

\section{Functional Form Specification and Results}

When estimating expenditure elasticities there are a variety of functional forms available. ${ }^{16}$ We will present results for three different specifications: double logarithmic, semi-logarithmic and the approach associated with Working and Leser which relates budget share to the $\log$ of total expenditure. The respective functional forms for these specifications are:

$$
\begin{aligned}
\log q_{i}^{h} & =a+b \log x^{h} \\
q_{i}^{h} & =a+b \log x^{h} \\
w_{i}^{h} & =a+b \log x^{h}
\end{aligned}
$$

where $q_{i}^{h}$ is the consumption of item $i$ by household $h, w_{i}^{h}$ is the budget share of the good in question and $x_{10}$ is total expenditure of household $h$.

However, a further complication arises from the fact that some of the deprivation indicators are items which may be characterised by infrequency of purchase. Thus while no expenditure on clothes may be observed for the period over which the household keeps records, this does not imply that there is no consumption of the services of clothes. When modelling expenditure elasticities for items which potentially fall into these categories, and for which a high proportion of zero expenditures are observed, it is necessary to account for this. We do so via the Heckman two-stage model, which is well known from labour economics (Heckman, 1979). This involves separately modelling the decision whether to purchase or not and the decision of how much to purchase and it implies that there is a process whereby households select themselves into the group for which non-zero observations are recorded. ${ }^{17}$ The resulting expenditure elasticities estimated via the Heckman approach are then purged of the selectivity bias.

What sort of factors are likely to increase the probability that a household will record a non-zero expenditure on an item such as clothing? Suppose that the average household member records expenditure on clothing $p$ times every year. Then in any given fourteen day period (the length of time for which diary records are kept in the Irish HBS) the probability of recording a zero expenditure on clothing for that person is $\max [0,1-p / 26]$. Now suppose a household consists of $n$ persons and assume that each of them also record expenditure on clothing $p$ times a year. Now the probability that the household will record zero expenditure on clothing is given by $\max \left[0,(1-p / 26)^{n}\right]$. Thus the probability of a non-zero expenditure being recorded is increasing in household size, $n .{ }^{18}$ Thus we can model the decision to purchase as a probit with household size and equivalised

\footnotetext{
${ }^{16}$ See Deaton and Muellbauer (1980, Chapter 1) for a discussion.

${ }^{17}$ For other approaches to this question see Kay, Keen and Morris (1984), Deaton and Irish (1984), Keen (1986) and Blundell and Meghir (1987).

${ }^{18}$ This assumes that people in the household make their purchases independently. Even if we were to modify this assumption it would still be the case that the probability of a non-zero expenditure being recorded is increasing in household size.
} 
expenditure as independent variables and then the second stage of the Heckman two-stage is simply given by the Engel curve specifications outlined above. Note that household size is also an attractive variable for identification since it affects the decision to purchase, but once expenditures have been adjusted to take account of household size and composition, it should have no effect on how much is purchased. We apply this procedure to those items where we observe a high proportion of zero observations: clothing, overcoat, shoes, holidays, savings, presents, newspapers and afternoon/evening out in previous two weeks.

A further complication which arises is that many of our items of interest are categorical rather than continuous variables. Thus either a household has an indoor toilet or it has not - the same is true of other housing durables. In this case we cannot estimate the double log or Working-Leser model, since we cannot take the $\log$ of zero (the case where a household does not have an indoor toilet) nor can we define a budget share for the relevant item. We could estimate a semilog version of a linear probability model (LPM), or alternatively employ a probit or logit specification. The use of an LPM is generally not advised, principally because the fitted values from the LPM are not constrained to lie in the $(0,1)$ interval, as is the case with the other models. ${ }^{19}$ However, for the calculation of expenditure elasticities evaluated at the mean or median of the distribution, this may not be too much of a problem. When a probit or logit is estimated the coefficient on income will give the change in probability of having the relevant durable for a infinitesimal change in the continuous variable (expenditure/ income). As usual, we will present results for all three specifications. ${ }^{20}$

Tables 2 and 3 gives the results for the expenditure elasticities for the various items for 1987 and $1994 .^{21}$ Since we are looking for some estimate of the overall expenditure elasticity of the deprivation indicators, this raises the question of how to aggregate the estimates. One possibility is to take a weighted average of the individual elasticities, but the problem here is that in some cases it is far from clear what the weights should be. For example, in looking at the housing and durables dimension what are the relative weights for bath/shower and an indoor toilet? This is true for any categorical variable i.e. where a household either has or has not got the item in question.

It is possible to calculate a weighted average for the items in the Basic Dimension category for which we have estimates: new clothes, meals with meat/ chicken/fish, a warm waterproof overcoat and shoes. Together these four items

\footnotetext{
${ }^{19}$ See Greene (1997) for a discussion of the linear probability model.

${ }^{20}$ In general the choice between a probit or logit model is based on convenience and results are rarely sensitive to the choice made. However one case where this choice may be important is where there are either proportionately many " 0 " or many " 1 " observations. This is true for some of the consumer durables here where most households possess them. So in this case it is important to present results for both models. It is also possible that consumption patterns for the non-categorical goods will differ according to possession or non-possession of caertain categorical variables. We examined expenditure elasticities for non-categorical variables for those households with and without a bath, indoor toilet and central heating. While some differences were observed there was no systematic pattern.

${ }^{21}$ We indicate whether the expenditure elasticities are significantly different from zero. In Tables $2 \mathrm{~A}$ and $3 \mathrm{~A}$ we also present test statistics for the alternative null hypothesis that the elasticities are equal to unity. Note that should a good have a unitary elasticity then its use as a means of identifying the poor disappears since consumption by rich and poor alike will be (proportionally) identical. I am grateful to an anonymous referee for this point.
} 
TABLE 2

L-STYle Deprivation Indicators: ExPENDITURE Elasticities, 1987

\begin{tabular}{|c|c|c|c|c|}
\hline $\begin{array}{l}\text { ESRI Life-Style Deprivation Indicator } \\
\text { 1. Basic Dimension } \\
\text { Go without heat }\end{array}$ & \multicolumn{4}{|c|}{ Range of Expenditure Elasticities } \\
\hline $\begin{array}{l}\text { 1. Basic Dimension } \\
\text { Go without heat } \\
\text { Go without substantial meal } \\
\text { Debt/charity } \\
\text { New not second hand clothes } \\
\text { Meal with meat/chicken/fish } \\
\text { Warm, waterproof overcoat } \\
\text { Two pairs of strong shoes } \\
\text { Roast or equivalent once a week }\end{array}$ & $\begin{array}{l}1.11^{* *} \\
0.33^{* *} \\
1.10 \\
0.82^{* *}\end{array}$ & $\begin{array}{l}\text { SL } \\
\text { n.a. } \\
\text { n.a. } \\
\text { n.a. } \\
1.18^{* *} \\
0.35^{* *} \\
1.37^{* *} \\
0.84^{* *}\end{array}$ & $\begin{array}{l}1.16^{* *} \\
0.45^{* *} \\
1.33 \\
0.86\end{array}$ & $\begin{array}{l}1.15 \\
0.38 \\
1.27 \\
0.84\end{array}$ \\
\hline $\begin{array}{l}\text { 2. Housing/Durables Dimension } \\
\text { Bath/shower } \\
\text { Indoor toilet } \\
\text { Washing machine } \\
\text { Refrigerator } \\
\text { Colour TV } \\
\text { Dry, damp-free dwelling }\end{array}$ & $\begin{array}{l}\text { LPM } \\
0.09^{* *} \\
0.06^{* *} \\
0.17^{* *} \\
-0.08^{* *} \\
0.15^{* *}\end{array}$ & $\begin{array}{l}\text { Logit } \\
0.09^{* *} \\
0.06^{* *} \\
0.14^{* *} \\
-0.05^{* *} \\
0.12^{* *}\end{array}$ & $\begin{array}{r}\text { Probit } \\
0.08^{* *} \\
0.06^{* *} \\
0.13^{* *} \\
-0.05^{* *} \\
0.12^{* *} \\
\end{array}$ & $\begin{array}{c}\text { Average } \\
0.09 \\
0.06 \\
0.15 \\
-0.05 \\
0.13\end{array}$ \\
\hline $\begin{array}{l}\text { 3. Secondary Dimension } \\
\text { Telephone } \\
\text { Car } \\
\text { Ability to save regularly } \\
\text { Central heating } \\
\text { Annual holiday away from home }\end{array}$ & $\begin{array}{l}\text { LPM } \\
0.59^{* *} \\
0.54^{* *} \\
0.39^{* *} \\
0.56^{* *} \\
0.81^{* *} \\
\text { DL } \\
2.02^{* *} \\
0.90^{* *} \\
0.78^{* *}\end{array}$ & $\begin{array}{l}\text { Logit } \\
0.38^{* *} \\
0.41^{* *} \\
0.09^{* *} \\
0.34^{* *} \\
0.40^{* *} \\
\text { SL } \\
2.27^{* *} \\
0.82^{* *} \\
0.86^{* *}\end{array}$ & $\begin{array}{c}\text { Probit } \\
0.37^{* *} \\
0.38^{* *} \\
0.09^{* *} \\
0.32^{* *} \\
0.39^{* *} \\
\mathrm{WL} \\
2.27^{*} \\
1.01 \\
0.87^{*} \\
\end{array}$ & $\begin{array}{c}\text { Average } \\
0.45 \\
0.45 \\
0.19 \\
0.41 \\
0.53 \\
\text { Average } \\
2.19 \\
0.91 \\
0.84\end{array}$ \\
\hline
\end{tabular}

Note: **Significant at $1 \% ; *$ significant at $5 \%$.

DL: $\log q_{i}^{h}=a+b \log x^{h}$.

SL: $q_{i}^{h}=a+b \log x^{h}$.

WL: $w_{i}^{h}=a+b \log x^{h}$.

account for about 15 percent of total expenditure and their weights within that are 35 percent, 55 percent, 1 percent and 9 percent respectively (this is the case for both 1987 and 1994). On that basis the weighted average of the expenditure elasticities for the basic dimension of deprivation for 1987 is approximately 0.7 .

All the variables in the Housing/Durables dimension are categorical. The weighted average for the expenditure elasticities for the non-categorical variables in the Secondary dimension is approximately 1.2 (they have a share of about 3 percent in total expenditure). Combining this with the basic dimension we obtain a weighted average for these variables of 0.78 .

As noted above, the difficulty with obtaining an average for the expenditure elasticities for the categorical variables is that there are no available weights. Taking unweighted averages we obtain an overall elasticity for Housing/Durables of around 0.08 . The unweighted average for the categorical variables in the Secondary dimension is 0.4 . In total this gives an unweighted average for the categorical variables of about 0.24 .

In terms of getting an overall average, and hence an estimate for $\rho$, a simple unweighted average of the categorical and non-categorical variables gives a value 
TABLE 2A

Life-Style Deprivation Indicators, 1987, Chi-Square Test Statistic for Null HyPOTHESIS THAT EXPENDITURE ElasticITY EQUALS UNITY

\begin{tabular}{|c|c|c|c|}
\hline \multirow{2}{*}{$\frac{\text { ESRI Life-Style Deprivation Indicator }}{\text { 1. Basic Dimension }}$} & \multicolumn{3}{|c|}{ Range of Expenditure Elasticities } \\
\hline & DL & SL & WL \\
\hline Go without heat & & n.a. & \\
\hline Go without substantial meal & & n.a. & \\
\hline Debt/charity & & n.a. & \\
\hline New not second hand clothes & $6.68^{* *}$ & $17.76^{* *}$ & $24.34 * *$ \\
\hline Meal with meat/chicken/fish & $2513.58^{* *}$ & $1558.68^{* *}$ & $779.32^{* *}$ \\
\hline Warm, waterproof overcoat & 0.00 & 0.01 & 0.01 \\
\hline Two pairs of strong shoes & $4.28^{*}$ & 2.87 & 1.95 \\
\hline Roast or equivalent once a week & & & n.a. \\
\hline 2. Housing/Durables Dimension & LPM & Logit & Probit \\
\hline Bath/shower & $26528.7^{* *}$ & $24141.06^{* *}$ & $76.96^{* *}$ \\
\hline Indoor toilet & $38428.4^{* *}$ & $35726.3^{* *}$ & $99.98^{* *}$ \\
\hline Washing machine & $6641.26^{* *}$ & $9976.11^{* *}$ & $396.71 * *$ \\
\hline Refrigerator & $7439.63 * *$ & $14205.98^{* *}$ & $2053.77 * *$ \\
\hline Colour TV & $7236.36^{* *}$ & $10744.68^{* *}$ & $437.2^{* *}$ \\
\hline Dry, damp-free dwelling & & n.a & \\
\hline 3. Secondary Dimension & LPM & Logit & Probit \\
\hline Telephone & $648.91 * *$ & $2527.67 * *$ & $6.11^{*}$ \\
\hline Car & $1128.2^{* *}$ & $2207.3 * *$ & 1.16 \\
\hline Ability to save regularly & $316.23 * *$ & $11807.53^{* *}$ & $640.59 * *$ \\
\hline Central heating & $660.8 * *$ & $3262.96^{* *}$ & $46.55^{* *}$ \\
\hline \multirow[t]{2}{*}{ Annual holiday away from home } & $78.89 * *$ & $2354.5^{* *}$ & 0.00 \\
\hline & $\mathrm{DL}$ & SL & WL \\
\hline Presents for family/friends once a year & $3.41 *$ & $4.81^{*}$ & $4.37^{*}$ \\
\hline Daily newspaper & $6.13^{*}$ & $18.81 * *$ & 0.06 \\
\hline Afternoon/evening out in previous two weeks & $17.89 * *$ & 2.58 & $6.42^{*}$ \\
\hline Hobby/leisure activity & & n.a & \\
\hline
\end{tabular}

Note: **Significant at $1 \% ; *$ significant at $5 \%$.

DL: $\log q_{i}^{h}=a+b \log x^{h}$.

SL: $g_{i}^{h}=a+b \log x^{h}$.

WL: $w_{i}^{h}=a+b \log x^{h}$.

of $0.5,{ }^{22}$ In the tables below we present results for this value $(\rho=0.5)$ and also for the case where we take $\rho$ to be equal to the weighted average of the elasticities of the basic dimension of deprivation, i.e. $\rho=0.7$.

We now investigate how measured poverty is sensitive to the choice of the income elasticity of the poverty line. We present results from Ireland using four values of $\rho: 0,1$ and 0.5 and 0.7 , the values based on the deprivation approach. Intuitively lower values of $\rho$ will give lower increases (or greater decreases) in measured poverty but the extent to which this occurs is still of interest. We present this information using six different measures of the poverty line: 40 percent, 50 percent and 60 percent of mean and median income respectively. We then adjust these to take account of zero real growth $(\rho=0)$, growth by the actual real growth in mean/median expenditure $(\rho=1)$ and growth by 50 percent and 70 percent of actual real growth $(\rho=0.5$ and 0.7$)$ and the results are in Table 4 . We then present poverty measures for three different aggregation indices: the headcount ratio, the income gap ratio and the Foster-Greer-Thorbecke $P_{\alpha}$ measure when $P=2$.

${ }^{22}$ When we carry out a similar procedure for 1994 we also obtain a figure of approximately 0.5 . 
TABLE 3

Life-Style Deviation Indicators: Expenditure Elasticities, 1994

\begin{tabular}{|c|c|c|c|c|}
\hline \multirow{2}{*}{$\frac{\text { ESRI Life-Style Deprivation Indicator }}{\text { 1. Basic Dimension }}$} & \multicolumn{4}{|c|}{ Range of Expenditure Elasticities } \\
\hline & DL & SL & WL & Average \\
\hline Go without heat & \multicolumn{4}{|c|}{ n.a. } \\
\hline Go without substantial meal & \multicolumn{4}{|c|}{ n.a. } \\
\hline Debt/charity & \multicolumn{4}{|c|}{ n.a. } \\
\hline New not second hand clothes & $1.17^{* *}$ & $1.27^{* *}$ & $1.21^{* *}$ & 1.22 \\
\hline Meal with meat/chicken/fish & $0.24^{* *}$ & $0.26^{* *}$ & $0.38^{* *}$ & 0.29 \\
\hline Warm, waterproof overcoat & 1.67 & 1.73 & 1.67 & 1.69 \\
\hline Two pairs of strong shoes & $0.80^{* *}$ & $0.76^{* *}$ & 0.79 & 0.78 \\
\hline Roast or equivalent once a week & \multicolumn{4}{|c|}{ n.a. } \\
\hline 2. Housing/Durables Dimension & LPM & Logit & Probit & Average \\
\hline Bath/shower & $0.06^{* *}$ & $0.06^{* *}$ & $0.05^{* *}$ & 0.06 \\
\hline Indoor toilet & $0.04 * *$ & $0.04 * *$ & $0.03^{* *}$ & 0.04 \\
\hline Washing machine & $0.17^{* *}$ & $0.16^{* *}$ & $0.14^{* *}$ & 0.16 \\
\hline Refrigerator & $-0.17^{* *}$ & $-0.09 * *$ & $-0.09 * *$ & -0.12 \\
\hline Colour TV & $0.05^{* *}$ & $0.05^{* *}$ & $0.05^{* *}$ & 0.05 \\
\hline Dry, damp-free dwelling & n.a & & & \\
\hline 3. Secondary Dimension & LPM & Logit & Probit & Average \\
\hline Telephone & $0.30^{* *}$ & $0.26^{* *}$ & $0.24 * *$ & 0.27 \\
\hline Car & $0.56^{* *}$ & $0.47^{* *}$ & $0.43 * *$ & 0.49 \\
\hline Ability to save regularly & $0.46^{* *}$ & $0.12 * *$ & $0.13^{* *}$ & 0.24 \\
\hline Central heating & $0.43^{* *}$ & $0.36^{* *}$ & $0.33^{*}$ & 0.37 \\
\hline \multirow[t]{2}{*}{ Annual holiday away from home } & $0.88^{* *}$ & $0.41^{* *}$ & $0.39 * *$ & 0.56 \\
\hline & DL & SL & WL & Average \\
\hline Presents for family/friends once a year & $2.15^{* *}$ & $2.30^{* *}$ & 2.12 & 2.19 \\
\hline Daily newspaper & $1.01^{* *}$ & $0.92^{* *}$ & 1.13 & 1.02 \\
\hline Afternoon/evening out in previous two weeks & $0.84^{* *}$ & $0.93^{* *}$ & $0.94^{* *}$ & 0.90 \\
\hline Hobby/leisure activity & & n.a. & & \\
\hline
\end{tabular}

Note: **Significant at $1 \%$; *significant at $5 \%$.

DL: $\log q_{i}^{h}=a+b \log x^{h}$.

SL: $q_{i}^{h}=a+b \log x^{h}$.

WL: $w_{i}^{h}=a+b \log x^{h}$.

Since these poverty measures are estimated on the basis of sample observations we need to test whether observed differences in their values are statistically significant. Kakwani (1990) has derived formulae for the standard errors of a number of poverty measures including the three we use here. The formulae for the test statistic are given in the appendix. In the results that follow we indicate whether the poverty measure is significantly different from poverty in 1987.

Table 5 gives the headcount ratio based on these measures. Suppose we have $n$ households and the poverty line is $z$. Then if $q$ households have expenditures below $z$, the headcount ratio is simply $H=q / n$. Predictably measures for all poverty lines show a fall when $\rho=0$ and they are all statistically significant, all but one at the 1 percent level. In no other case is poverty significantly different from its 1987 level. Thus we cannot reject the hypothesis that when $\rho$ takes on values of $0.5,0.7$ and 1 measured poverty is unchanged between 1987 and 1994 .

However the headcount ratio has a number of deficiencies as a poverty measure, the most important of which are the fact that it takes no account of the depth of poverty and that it does not satisfy the principle of transfers (i.e. it is unchanged following a transfer of income from poor to a less poor household 
TABLE 3A

Life-Style Deprivation Indicators, 1994, Test Statistic for Null Hypothesis that EXPEnditure Elasticity Equals UNITY

\begin{tabular}{|c|c|c|c|}
\hline \multirow{2}{*}{$\begin{array}{l}\text { ESRI Life-Style Deprivation Indicator } \\
\text { 1. Basic Dimension }\end{array}$} & \multicolumn{3}{|c|}{ Range of Expenditure Elasticities } \\
\hline & DL & SL & WL \\
\hline Go without heat & & n.a. & \\
\hline Go without substantial meal & & n.a. & \\
\hline Debt/charity & & n.a. & \\
\hline New not Ssecond hand clothes & $16.28 * *$ & $36.29^{* *}$ & $35.61^{* *}$ \\
\hline Meal with meat/chicken/fish & $2902.35^{* *}$ & $1821.84^{* *}$ & $889.26^{* *}$ \\
\hline Warm, waterproof overcoat & 0.03 & 0.04 & 0.03 \\
\hline Two pairs of strong shoes & 3.63 & $5.52^{*}$ & 3.29 \\
\hline Roast or equivalent once a week & & n.a. & \\
\hline 2. Housing/Durables Dimension & LPM & Logit & Probit \\
\hline Bath/shower & $67238.3^{* *}$ & $53264.15 * *$ & $20.70^{* *}$ \\
\hline Indoor toilet & $98421.7^{* *}$ & $87322.87 * *$ & $33.35^{* *}$ \\
\hline Washing machine & $17997.3^{* *}$ & $12496.76^{* *}$ & $85.40^{* *}$ \\
\hline Refrigerator & $13622.2^{* *}$ & $13023.49^{* *}$ & $2641.64^{* *}$ \\
\hline Colour TV & $42005.8^{* *}$ & $39895.37^{* *}$ & $290.33 * *$ \\
\hline Dry, damp-free dwelling & n.a & & \\
\hline 3. Secondary Dimension & LPM & Logit & Probit \\
\hline Telephone & $10322.4^{* *}$ & $5729.31 * *$ & $32.86^{* *}$ \\
\hline $\mathrm{Car}$ & $6439.17^{* *}$ & $1650.38^{*}$ & $47.91^{* *}$ \\
\hline Ability to save regularly & $11369.1^{* *}$ & 10054.76 & $556.36^{* *}$ \\
\hline Central heating & $7650.95^{* *}$ & $3524.03^{* *}$ & 2.16 \\
\hline \multirow[t]{2}{*}{ Annual holiday away from home } & $6376.78^{* *}$ & $2389.95^{* *}$ & 1.41 \\
\hline & $\mathrm{DL}$ & SL & WL \\
\hline Presents for family/friends once a year & 2.38 & 2.45 & 0.96 \\
\hline Daily newspaper & 0.02 & 1.51 & 2.26 \\
\hline Afternoon/evening out in previous two weeks & $9.54^{* *}$ & 0.95 & 1.18 \\
\hline Hobby/leisure activity & & n.a & \\
\hline
\end{tabular}

Note: ${ }^{* *}$ Significant at $1 \% ;{ }^{*}$ significant at $5 \%$.

DL: $\log q_{i}^{h}=a+b \log x^{h}$.

$\mathrm{SL}: q_{i}^{h}=a+b \log x^{h}$.

WL: $w_{i}^{h}=a+b \log x^{h}$.

when both households are below the poverty line). The first of these deficiencies can be remedied by the choice of an income gap measure as our poverty measure. The income gap measure sums all the proportionate shortfalls below the poverty line for poor households: $\sum_{i=1}^{q}\left(z-y_{i}\right) / z$.. This measure is then normalised by dividing by the total number of households, $n$. This can also be expressed as H.I where $I=\left(z-\bar{y}_{p}\right) / z$ and $\bar{y}_{p}$ is average income for poor households. This measure takes account of the depth of poverty but does not satisfy the principle of transfers. $^{23}$

Table 6 shows changes in poverty using this measure. Once again when $\rho=$ 0 we observe falls in poverty all but one of which are statistically significant. Once again when $\rho$ takes on values of $0.5,0.7$ or 1 we observe poverty to be unchanged or rising but only for the case where the poverty line is set at 40 percent of median income and $\rho=1$ is this found to be significant. Since this is also precisely the poverty line where no fall in poverty is observed when $\rho=0$ and is also the lowest poverty line, it suggests that the very poorest did not fare well between 1987 and

${ }^{23}$ This also corresponds to the Foster-Greer-Thorbecke $\mathrm{P}_{\alpha}$ measure when $\alpha=1$. 
TABLE 4

Poverty Lines for WeEkly EXPENditure (AdJUSTed for FAmily Size AND COMPOSITION, IR£, 1987), 1987 AND 1994

\begin{tabular}{lccccccc}
\hline \hline & \multicolumn{3}{c}{ Mean } & & \multicolumn{3}{c}{ Median } \\
\cline { 2 - 4 } \cline { 6 - 8 } & $40 \%$ & $50 \%$ & $60 \%$ & & $40 \%$ & $50 \%$ & $60 \%$ \\
\hline 1987 & 37.73 & 47.16 & 56.60 & & 30.99 & 38.73 & 46.48 \\
$1994, \rho=0$ & 37.73 & 47.16 & 56.60 & & 30.99 & 38.73 & 46.48 \\
$1994, \rho=0.5$ & 38.95 & 48.68 & 58.42 & & 32.06 & 40.07 & 48.09 \\
$1994, \rho=0.7$ & 39.45 & 49.32 & 59.18 & & 32.50 & 40.62 & 48.73 \\
$1994, \rho=1$ & 40.19 & 50.24 & 60.29 & & 33.15 & 41.43 & 49.70 \\
\hline
\end{tabular}

TABLE 4A

Poverty Lines for WeEkly Disposable Income (Adjusted for FAmily Size AND COMPOSITION, IRE, 1987), 1987 AND 1994

\begin{tabular}{lccccccc}
\hline \hline & \multicolumn{3}{c}{ Mean } & & \multicolumn{3}{c}{ Median } \\
\cline { 2 - 4 } \cline { 7 - 8 } & $40 \%$ & $50 \%$ & $60 \%$ & & $40 \%$ & $50 \%$ & $60 \%$ \\
\hline 1987 & 33.58 & 41.98 & 50.38 & & 26.81 & 33.51 & 40.21 \\
$1994, \rho=0$ & 33.58 & 41.98 & 50.38 & & 26.81 & 33.51 & 40.21 \\
$1994, \rho=0.5$ & 37.08 & 46.35 & 55.62 & & 29.28 & 36.60 & 43.92 \\
$1994, \rho=0.7$ & 38.50 & 48.13 & 57.75 & & 30.28 & 37.84 & 45.41 \\
$1994, \rho=1$ & 40.61 & 50.77 & 60.92 & & 31.76 & 39.70 & 47.64 \\
\hline
\end{tabular}

TABLE 5

Percentage of Households Below Poverty Lines in Table 4

\begin{tabular}{lccccccc}
\hline \hline & \multicolumn{3}{c}{ Mean } & & \multicolumn{3}{c}{ Median } \\
\cline { 2 - 4 } \cline { 6 - 8 } & $40 \%$ & $50 \%$ & $60 \%$ & & $40 \%$ & $50 \%$ & $60 \%$ \\
\hline 1987 & 9.9 & 19.6 & 29.5 & & 4.9 & 11.0 & 18.9 \\
$1994, \rho=0$ & $8.8^{*}$ & $17.3^{* *}$ & $26.6^{* *}$ & & $3.8^{* *}$ & $9.5^{* *}$ & $16.9^{* *}$ \\
$1994, \rho=0.5$ & 9.7 & 18.7 & 28.6 & & 4.5 & 10.7 & 18.1 \\
$1994, \rho=0.7$ & 10.1 & 19.3 & 29.2 & & 4.8 & 11.2 & 18.7 \\
$1994, \rho=1$ & 10.8 & 20.1 & 30.2 & & 5.3 & 11.8 & 19.6 \\
\hline
\end{tabular}

TABLE 5A

Percentage of Households Below Poverty Lines in Table 4A

\begin{tabular}{|c|c|c|c|c|c|c|}
\hline & \multicolumn{3}{|c|}{ Mean } & \multicolumn{3}{|c|}{ Median } \\
\hline & $40 \%$ & $50 \%$ & $60 \%$ & $40 \%$ & $50 \%$ & $60 \%$ \\
\hline 1987 & 7.3 & 16.3 & 27.1 & 2.1 & 7.2 & 14.3 \\
\hline $1994, \rho=0$ & $2.2^{* *}$ & $7.3^{* *}$ & $15.4^{* *}$ & $1.2^{* *}$ & $2.2^{* *}$ & $5.9^{* *}$ \\
\hline $1994, p=0.5$ & $3.7^{* *}$ & $11.2^{* *}$ & $23.1 * *$ & $1.5^{* *}$ & $3.4^{* *}$ & $9.2 * *$ \\
\hline $1994, \rho=0.7$ & $4.6^{* *}$ & $13.0^{* *}$ & 26.4 & $1.6^{*}$ & $4.1^{* *}$ & $10.5^{* *}$ \\
\hline $1994, \rho=1$ & $6.2^{* *}$ & 16.8 & $31.3^{* *}$ & 1.8 & $5.5^{* *}$ & $12.6^{* *}$ \\
\hline
\end{tabular}

1994. When higher poverty lines are used then the improvement in the situation of the relatively better off amongst the poor outweighs this.

To take account of the principle of transfers we use the Foster-Greer-Thorbecke $\mathrm{P}_{\alpha}$ measure when $\alpha=2$. This measure weights the income gaps by the gaps 
TABLE 6

Normalised Income Gap Ratio for Poverty Lines in Table 4

\begin{tabular}{llllllll}
\hline \hline & \multicolumn{3}{c}{ Mean } & & \multicolumn{3}{c}{ Median } \\
\cline { 2 - 4 } \cline { 6 - 8 } & $40 \%$ & $50 \%$ & $60 \%$ & & $40 \%$ & $50 \%$ & $60 \%$ \\
\hline 1987 & 0.021 & 0.046 & 0.079 & & 0.009 & 0.023 & 0.044 \\
$1994, \rho=0$ & $0.018^{*}$ & $0.040^{* *}$ & $0.070^{* *}$ & & 0.008 & $0.020^{*}$ & $0.038^{* *}$ \\
$1994, \rho=0.5$ & 0.020 & 0.045 & 0.076 & & 0.009 & 0.022 & 0.043 \\
$1994, \rho=0.7$ & 0.021 & 0.046 & 0.079 & & 0.010 & 0.024 & 0.045 \\
$1994, \rho=1$ & 0.022 & 0.049 & 0.083 & & $0.011^{*}$ & 0.025 & 0.047 \\
\hline
\end{tabular}

* Poverty different from 1987 at $5 \%$ level.

**Poverty different from 1987 at $1 \%$ level.

TABLE 6A

NORMALISED INCOME GAP RATIO FOR POVERTY LINES IN TABLE 4A

\begin{tabular}{llllllll}
\hline \hline & \multicolumn{3}{c}{ Mean } & & \multicolumn{3}{c}{ Median } \\
\cline { 2 - 5 } \cline { 6 - 8 } & $40 \%$ & $50 \%$ & $60 \%$ & & $40 \%$ & $50 \%$ & $60 \%$ \\
\hline 1987 & 0.015 & 0.036 & 0.065 & & 0.009 & 0.015 & 0.031 \\
$1994, \rho=0$ & $0.008^{* *}$ & $0.015^{* *}$ & $0.031^{* *}$ & & $0.006^{* *}$ & $0.008^{* *}$ & $0.013^{* *}$ \\
$1994, \rho=0.5$ & $0.010^{* *}$ & $0.023^{* *}$ & $0.047^{* *}$ & & 0.007 & $0.010^{* *}$ & $0.018^{* *}$ \\
$1994, \rho=0.7$ & $0.011^{* *}$ & $0.026^{* *}$ & $0.054^{* *}$ & & 0.007 & $0.011^{* *}$ & $0.021^{* *}$ \\
$1994, \rho=1$ & 0.013 & $0.032^{*}$ & 0.066 & & 0.007 & $0.012^{*}$ & $0.025^{* *}$ \\
\hline
\end{tabular}

${ }^{*}$ Poverty different from 1987 at $5 \%$ level

**Poverty different from 1987 at $1 \%$ level

TABLE 7

FGT $P_{\alpha}(\alpha=2)$ For Poverty Lines in Table 4

\begin{tabular}{lccccccc}
\hline \hline & \multicolumn{3}{c}{ Mean } & & \multicolumn{3}{c}{ Median } \\
\cline { 2 - 4 } \cline { 6 - 8 } & $40 \%$ & $50 \%$ & $60 \%$ & & $40 \%$ & $50 \%$ & $60 \%$ \\
\hline 1987 & 0.0066 & 0.0162 & 0.0304 & & 0.0027 & 0.0074 & 0.0153 \\
$1994, \rho=0$ & 0.0062 & $0.0142^{*}$ & $0.0266^{* *}$ & & 0.0031 & 0.0068 & $0.0135^{*}$ \\
$1994, \rho=0.5$ & 0.0069 & 0.0160 & 0.0295 & & 0.0034 & 0.0078 & 0.0153 \\
$1994, \rho=0.7$ & 0.0073 & 0.0167 & 0.0307 & & $0.0036^{*}$ & 0.0082 & 0.0160 \\
$1994, \rho=1$ & 0.0078 & 0.0178 & 0.0325 & & $0.0038^{*}$ & $0.0088^{*}$ & $0.0172^{*}$ \\
\hline
\end{tabular}

*Poverty different at $5 \%$ level.

**Poverty different at $1 \%$ level.

TABLE 7A

FGT $P_{\alpha}(\alpha=2)$ For Poverty Lines in TABle 4A

\begin{tabular}{llllllll}
\hline \hline & \multicolumn{3}{c}{ Mean } & & \multicolumn{3}{c}{ Median } \\
\cline { 2 - 4 } \cline { 6 - 8 } & $40 \%$ & $50 \%$ & $60 \%$ & & $40 \%$ & $50 \%$ & $60 \%$ \\
\hline 1987 & 0.0080 & 0.0142 & 0.0252 & & 0.0060 & 0.0080 & 0.0125 \\
$1994, \rho=0$ & $0.0052^{* *}$ & $0.0073^{* *}$ & $0.0120^{* *}$ & & 0.0042 & $0.0052^{* *}$ & $0.0067^{* *}$ \\
$1994, \rho=0.5$ & $0.0059^{*}$ & $0.0094^{* *}$ & $0.0169^{* *}$ & & 0.0046 & $0.0058^{*}$ & $0.0081^{* *}$ \\
$1994, \rho=0.7$ & 0.0062 & $0.0104^{* *}$ & $0.0193^{* *}$ & & 0.0047 & 0.0061 & $0.0088^{* *}$ \\
$1994, \rho=1$ & 0.0068 & 0.0123 & 0.0234 & & 0.0049 & 0.0066 & $0.0101^{*}$ \\
\hline
\end{tabular}

*Poverty different at $5 \%$ level.

**Poverty different at $1 \%$ level. 
themselves thus awarding a higher weight to poorer households. Thus we have $\left.P_{2}=(1 / n) \sum_{y_{i}<p}\left[z-y_{i}\right) / z\right]^{2}$. The results for this measure of poverty are more mixed. When $\rho=0$ then three of the six poverty lines show a statistically significant fall in poverty between 1987 and 1994 . When $\rho=0.5$, there is no statistically significant change in poverty. When $\rho=0.7$ then only when the poverty line is 40 percent of median income do we see a statistically significant rise in poverty. When $\rho=1$ there is a statistically significant rise in poverty when our poverty line is based on median expenditure but not when it is based on mean expenditure. Once again this suggests that it is the fortunes of the relatively poorer among those below the poverty line who are driving this result since the poverty lines based on median expenditure are lower than those based on mean expenditure.

These results are in contrast to the results of Callan et al. who found that poverty fell for all poverty lines when using an income gap measure. However they used disposable income rather than expenditure and they do not indicate whether their reported changes in measured poverty are statistically significant. To allow closer comparison with their results in Tables 4A to 7A we reproduce the above analysis but using disposable income as opposed to expenditure. ${ }^{24}$ Our results for income are more in line with those of Callan et al. although we do not record such large falls in the income gap nor in the $\mathrm{P}_{\alpha}$ measure. However in no cases do we observe a statistically significant rise in poverty when $\rho=1$.

On the basis of these results the overall conclusions which can be drawn are: when $\rho=0$, i.e. when we use an absolute poverty line we observe statistically significant falls in poverty for nearly all the poverty lines and poverty measures chosen. When $\rho=1$ there is some evidence of a statistically significant rise in poverty when poverty lines are drawn up on the basis of median expenditure, but none when mean expenditure is used. When intermediate values of $\rho$, based on the expenditure elasticities of life-style and deprivation indicators, are used then there is no statistically significant difference between poverty in 1987 and 1994 . When disposable income is used we observe statistically significant falls in poverty for cases where $\rho=0,0.5$ and 0.7 . When using a purely relative poverty line in general we cannot reject the hypothesis that poverty is unchanged between 1987 and 1994.

The discrepancy between the results for income and expenditure is notable. While it is plausible that some consumption smoothing is going on, the results for relative poverty lines suggests that more consumption smoothing is being carried out by low-income households. If households believed that the boom in the Irish economy which began around 1993-94 (the advent of the so called "Celtic Tiger") was not permanent then it is to be expected that consumption would not rise as quickly as income. However, it is not clear why this effect is more pronounced among poor households. It may be due to greater precautionary saving on behalf of poor households which is consistent with the notion of

\footnotetext{
${ }^{24}$ In using disposable income we have not adjusted for top-coding. Top coding affects about 0.7 precent of the observations for 1987 and about 2 percent for 1994. Note that median based measures will not be affected by top-coding. Also we have dropped variables for which negative disposable income is recorded. While negative income is not unusual for self-employed their inclusion can complicate the calculation of gap and distributionally sensitive gap measures. In 1987 there were 5 out of 7,705 negative observations and in 199412 out of 7,877 so their exclusion is unlikely to alter the results significantly.
} 
decreasing absolute risk aversion. ${ }^{25}$ In future work we hope to investigate this in more detail.

A further issue which merits investigation is the extent to which the choice of $\rho$ affects the risk or incidence of poverty for different groups in society. This is also a potential topic for future research, given that many transfer programmes are carried out on a categorical rather than means-tested basis.

One should be careful about policy conclusions which can be drawn from this study. This paper is not arguing that income support payments which are designed to combat poverty should be indexed in line with the measure of $\rho$. To the extent that these payments are focussed upon those identified as below the poverty line, then this recommendation may follow. However, it should not be assumed that it follows automatically. Ultimately, the resources which society decides to devote to combat poverty is determined by the political process. However, the extent to which poverty is perceived as a problem will be influenced by the way in which it is measured and measurement will be influenced by the choice of $\rho$. The purpose of this paper is to show how different choices of $\rho$ may give rise to different results regarding the evolution of poverty in Ireland over the 1987-94 period. It also suggests an alternative method of arriving at a value of $\rho$ apart from choosing the extreme values of zero or unity. As discussed above it also shows how different results can be obtained depending upon whether poverty is measured with respect to income or total expenditure.

Thus the rather low-key, but nevertheless important, conclusion to be drawn from this paper is the continued importance of testing the sensitivity of our poverty measures to the various background assumptions.

\section{Conclusions}

This paper has advanced the study of poverty in Ireland in a number of directions. First it provides evidence on poverty based on total expenditure and disposable income using the Household Budget Surveys of 1987 and 1994. Secondly it addresses the issue of what value to choose for the expenditure elasticity of the poverty line by suggesting the expenditure elasticity of those items whose absence is identified as indicating deprivation. Thirdly, it calculates standard errors for the estimated poverty measures and indicates where changes in measured poverty are statistically significant. The results are not surprising. The use of an absolute poverty line (i.e. when the expenditure elasticity of the poverty line is zero) shows a statistically significant fall in poverty over the 1987-94 period. The use of a purely relative poverty line (an expenditure elasticity of the poverty line of one) provides limited evidence of a statistically significant rise in poverty over the period. The use of intermediate poverty lines (with expenditure elasticities of 0.5 and 0.7 ) suggests no statistically significant change in poverty over the period. Use of a disposable income measure alters these results and generally shows that poverty has either fallen or at worst remained unchanged over the period. (1990).

${ }^{25}$ For a formal discussion of the link between risk-aversion and precautionary saving see Kimball 


\section{Appendix: Testing for Differences in Poverty Measures}

Kakwani (1990) establishes the following tests of significance for differences in poverty measures: suppose $\hat{P}_{1}$ and $\hat{P}_{2}$ are estimates of poverty computed on the basis of two independently drawn random samples of sizes $n_{1}$ and $n_{2}$ respectively. Then if $\sigma_{1}^{2}$ and $\sigma_{2}^{2}$ are the sample estimators of the variances of the asymptotic distributors of $\sqrt{n_{1}} \hat{P}_{1}$ and $\sqrt{n_{1}} \hat{P}_{1}$ respectively the standard error of $\left(\hat{P}_{1}-\hat{P}_{2}\right)$ will be

$$
S E\left(\hat{P}_{2}-\hat{P}_{2}\right)=\sqrt{\frac{\sigma_{1}^{2}}{n_{1}}+\frac{\sigma_{2}^{2}}{n_{2}}}
$$

and the statistic $\eta=\left(\hat{P}_{1}-\hat{P}_{2}\right) / S E\left(\hat{P}_{1}-\hat{P}_{2}\right)$ has an asymptotic normal distribution with zero mean and unit variance. For the headcount ratio measure if $H_{i}$ is the proportion of households below the poverty line then $\hat{\sigma}_{i}^{2}=H_{i}\left(1-H_{i}\right)$. For the FGT $P_{\alpha}$ measures then $\operatorname{var}\left(\sqrt{n} \hat{P}_{\alpha}\right)=\hat{P}_{2 \alpha}-\hat{P}_{\alpha}^{2}$ where $\hat{P}_{\alpha}=(1 / n) \sum_{i=1}^{q}\left[\left(z-y_{i}\right) / z\right]^{\alpha}$.

\section{REFERENCES}

Atkinson, A. B., The Economics of Inequality, Oxford University Press, Oxford, 1987.

Blundell, R., and C. Meghir, Bivariate Alternatives to the Tobit Model, Journal of Econometrics, Vol. 34, 179-200, 1987.

Blundell, R. C. Meghir, and I. Preston, Consumption Inequality and Income Uncertainty, Quarterly Journal of Economics, Vol. 113, 603-40, 1998.

Callan, T., B. Nolan, B. Whelan, C. Whelan and J. Williams, Poverty in the 1990s: Evidence from the Living in Ireland Survey, Oak Tree Press, Dublin, 1996.

Callan, T., B. Nolan, B. Whelan, and J. Walsh, Income Tax and Social Welfare Policies, in Budget Perspectives, Economic and Social Research Institute, Dublin, 1998

Caplovitz, D., The Poor Pay More: Consumer Practices of Low Income Families, Columbia University Press, New York, 1967.

Deaton, A. and J. Muellbauer, Economics and Consumer Behaviour, Cambridge University Press, Cambridge, 1980.

Deaton, A., J. Muellbauer, and M. Irish, Statistical Models for Zero Expenditures in Household Budgets, Journal of Public Economics, Vol. 23, pp. 59-80, 1984.

Desai, M., and A. Shah, An Econometric Approach to the Measurement of Poverty, Oxford Economic Papers, Vol. 40, 505-22, 1988.

Foster, J., Absolute versus Relative Poverty, American Economic Review, Vol. 88, 335-41, 1998.

Foster, J., J. Greer and E. Thorbecke, A Class of Decomposable Poverty Measures, Econometrica, Vol. 52, 761-66, 1984.

Gray, A., Irish Economic Challenges and International Perspectives in A. Gray, ed. International Perspectives on the Irish Economy, Indecon Public Policy Series, Dublin,1997.

Greene, W., Econometric Analysis (3rd ed.), Prentice-Hall International, London, 1997.

Heckman, J., Sample Selection as a Specification Error, Econometrica, Vol. 47, 153-61, 1979.

Kakwani, N., Testing for Significance of Poverty Differences, World Bank LSMS Working Paper No. $62,1990$.

Kay, J., M. Keen and C. Morris, Estimating Consumption from Expenditure Data, Journal of Public Economics, Vol. 23, 169-81, 1984.

Kimball, M., Precautionary saving in the Small and the Large, Econometrica, Vol. 58, pp. 53-73, 1990.

Mack, J., and S. Lansley, Poor Britain, Allen and Unwin, London, 1985.

O'Neill, D., and O. Sweetman, Poverty and Inequality in Ireland 1987-1994: A Comparison Using Measures of Income and Consumption, mimeo, 1998.

Sen, A., Poverty: An Ordinal Approach to Measurement, Econometrica, Vol. 44, 219-31, 1976.

Townsend, P., Poverty in the United Kingdom, Penguin, Harmondsworth, 1979. 